\title{
Networks as a Policy Instrument for Smaller Companies
}

\author{
1 Hans Jørgen Limborg \\ PhD, Research Director \& Partner Teamarbejdsliv
}

\section{Sisse Grøn}

PhD, Senior Researcher, Teamarbejdsliv

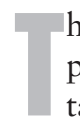

here is a growing focus upon the application of different policy instruments to improve health and safety, and how it is possible to evaluate their effect and their limitations (Hasle et al., 2014). The Invine Project (Limborg \& Groen, 2014), which is a part of the CAVI research group (CAVI, 2010), has raised the issue of the importance of networks among small businesses as means to a broader contact to this target group. We will start by picture ourselves in one of these small enterprises.

The Safety Representative at the Dairy fetched the new lifting device and brought it to the conveyer, where all the large cheeses were being loaded into cardboard boxes. "Let's use this, it is actually a great help, when you learn how to operate it", she said to a colleague who looked a little sceptic. "I know it's still a prototype, and it looks a little strange, but we took part in the development ourselves. Give it a chance!".

One and a half year earlier the Labour Inspector had issued a note to the company, ordering them to reduce heavy lifting. After an appeal they were given more time to solve the problems. The management was reluctant; they had no idea how to solve the problem, and did not want to invest too much as the competition was hard.

Not long after this event however, the manager was contacted by another manager of a Dairy in the western part of the country. He knew the caller well, as he had been ingenuitive in his approach to cheese production. And he had always been very active in the network of small Dairies, set up as a subgroup of the Dairy-employers association.

The caller suggested a joint application for a project to develop new lifting aids, since a new Prevention Fund enabled companies to apply for funding of development projects. They agreed to discuss it at the upcoming meeting in the network.

With the help of a qualified Occupational Health and Safety (OHS) consultant, they designed a project and received funding for the technical development of lifting aids, as well as for their own time consumption. Furthermore most of the other 22 dairies in the network also agreed to take part in the project. Some had had similar experiences to the one described above, with the Labour Inspection, others were simply aware of the wear and tear caused by the lifting operations. All had argued that they could not find the necessary means to cover the costs of the technical equipment to solve their lifting problems, if their competitors did not take on the same expense.

The manager from West Country Dairy was the pioneer in the process, he understood that if all agreed to participate by supporting the development project, the argument of competition would lose its power. He emphasized the need for mutual support, he even demanded that all managers in the network, one by one declared that they actively supported the project, and that they would open their plants for the networkmembers to visit for discussions and sharing of ideas related to the issue of reducing 
heavy lifting. This meeting was referred to as the "handshake meeting", and the tense atmosphere as they spoke out one by one, was remembered long after.

This historical development was documented by the Invine project (Limborg et al.), which analyzed the Dairy prevention project and two similar projects developed and executed by groups of small and medium-sized enterprises (SMEs).

It is a continuous challenge to ensure that SMEs are as healthy as any other workplace and it is well known that policy instruments directed at SMEs cannot simply be copied from policy instruments directed at large enterprises. But a more deliberate strategy toward Occupational Helath and Safety in SMEs is still in its making.

The main result from our study of three networks is that when it comes to OHS, SMEs are more affected by the actions and attitudes of their competitors and collaborators within their industry than they are affected by general campaigns, regulations and even by inspections from the Labor Inspectorate.

If this is true, it calls for reconsideration or a supplement to the previous strategy toward SMEs, which have mainly been closely matching the strategy toward large enterprises.

A new strategy should include support for the establishment and facilitation of networking between similar companies, as well as conclusion of agreements at industry level, agreements that can support the companies' joint effort to achieve a common commitment to meet the industry's safety standards.

The advantage of the above-mentioned approach is that it not only involves the companies and their associations but also the unions that represent the employee's interests in a healthy environment and thus would put pressure on the companies to take responsibility for the common standard of all companies in the industry, to meet the agreed standards. An additional advantage is that the approach will enable regulators to reach more companies than is possible with information campaigns or inspections.

It is of course crucial to create the necessary motivation to make this sort of agreements. The companies might be motivated if they know that they will not be imposed costs, greater than those imposed on their competitors, and also if they know that they will have support to solve problems they acknowledge frequently, but do not have solutions for. Another form of motivation can derive from making a "contract with society"; if they agree to raise the standard in the industry in general, they shall be recognized as good companies and be given more favorable operation conditions.

The latter seems the biggest challenge, for what can we offer the associations as a reward for their effort to raise the general standard? Previously, it has been an incentive to free the company of the threat of inspections from the Labor Inspectorate, as was the case with the OHS certificate (OHSAS 18001). This argument, however, seems vague, as companies that voluntarily improve their work environment are not likely to fear the Labor Inspectors' inspections. We should therefore consider attaching other incentives to such industry-level agreements, for example financial support to develop new technology or technical aids that would be accessible for all companies, as was the case for the dairies.

However, on the basis of our observations, the most important incentive seems to be recognition for one's effort, while those who fail to make the same effort are punished. Thus, the public focus on control and exposure of those who violate regulations must distinguish between the ones making an effort and those who are not, instead of issuing a collective punishment for all companies in the industry, which is in effect often the case today, when an industry is pinpointed as risky. 
Our study of the three networks shows that the companies are in favor of regulations, but they want to participate in defining the regulations and it is important to them that the agreements ensure that everyone, or as many as possible at least, are included, but accordingly, that those who do not wish to be, are exposed. This underlines the need to make the agreement and the names of the participating companies public.

The weakness of the proposed strategy is that the collective structures, on the employer's side as well as on the employees' side, are under pressure and seem to be in decline. Therefore, it is important that the associations and unions acknowledge such an agreement or network strategy as an enforcement of their position and legitimacy not only toward their members and potentials members especially, but also toward society in general.

On the basis of the experiences described above, we thus set new demands for policy instruments, meant to help the vast amount of existing SMEs prioritize and master their OHS challenges. Until now, the quality of policy instruments has been assessed on the basis of the number of possible recipients, the character of the message and their ability to induce action. Our results suggest that the potential of policy instruments should also be assessed based on their ability to:

- Separate the good from the bad companies

- Make use of the companies' interest in their competitors' initiatives, to let knowledge spread fast

- Provide a simple and wide-reaching information platform

- Set new OHS standards that are recognized by the companies

- Designate the successful ones, in order to make the companies appreciate regulation

- Help to define quality of work

- Provide a framework for a public dialog about quality, responsibility and distinctiveness

- Actively use the inclusion-exclusion mechanism in networks and associations.

This we believe will take us one step closer to a strategy for OHS improvements in SMEs that can create and build upon motivation from within.

\section{References}

Peter Hasle, Hans Jørgen Limborg \& Klaus T. Nielsen: Working environment interventions Bridging the gap between policy instruments and practice. Safety Science 2014, Vol. 68, p. $73-80$.

Limborg, Hans Jørgen, Maya Flensborg Jensen \& Sisse Grøn: Networking among small and medium-sized enterprises - meeting the challenge of promoting safety and health measures. International journal of Small Enterprise Research Forthcoming November 2014.

CAVI: Center for forskning i arbejdsmiljøindsatser og virkemidler. See: http://vbn.aau.dk/en/ projects/center-for-forskning-i-arbejdsmiljoeindsatser-og-virkemidler $(46573 \mathrm{e} 1 \mathrm{~b}-22 \mathrm{cb}$ 4b92-8584-d77027d38476).html. 